\title{
Reference indices for evaluating kidney dimensions in children using anthropometric measurements
}

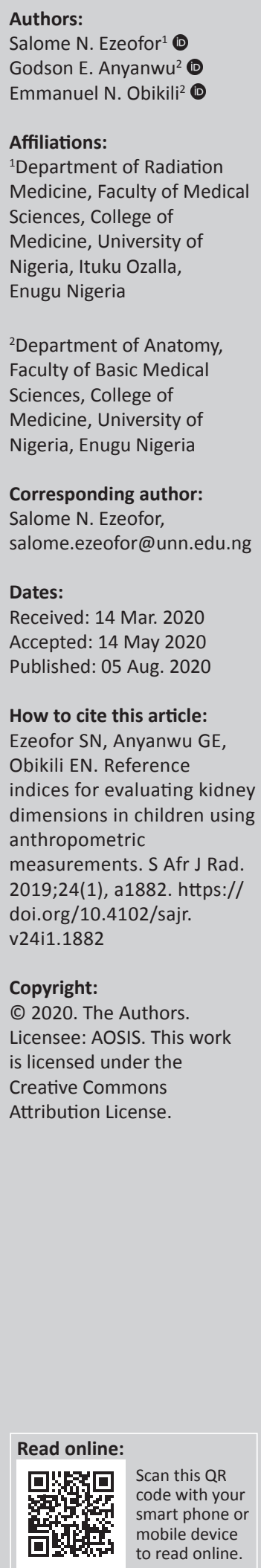

Background: Kidney pathologies often result in change in renal size. Knowledge of normal kidney sizes is important for screening, diagnosis, prognosis and follow-up management of paediatric renal diseases.

Objectives: The aim of this study was to establish the age-, height- and weight-matched kidney dimensions in apparently healthy Nigerian children.

Method: A descriptive, cross-sectional study of right and left kidney parameters (length, width, thickness and volume) of 1315 school-aged Nigerian children was conducted over 8 months. Ages ranged from 5 to 17 years. Parameters were obtained using a General Electric (GE) LOGIC 400CL ultrasound machine. Kidney dimensions were correlated with age, sex and anthropometric measurements.

Results: Normative values for all the kidney parameters for each age, height and weight groups and also gender were established for the study population. The left kidneys were noted to be longer and thicker, and of more volume than the right kidneys. The right kidneys were seen to be wider $(p<0.01)$. Length of the left kidneys in females was noted to be more than those of the males in the age- and weight-matched categories $(p<0.05)$. The width of both kidneys was higher in the males in all the categories $(p<0.05)$. Males showed higher values of thickness and volume in the height category. All the renal parameters significantly correlated with body size indicators, except for body mass index.

Conclusion: This study has established gender-, age-, weight- and height-specific range of values of the kidney parameters of apparently healthy children together with regression models.

Keywords: Kidney; Renal sizes; Children; Ultrasound; Nigeria.

\section{Introduction}

Anomalies of renal sizes are associated with and are manifestations of diseases involving the kidneys. ${ }^{1}$ The importance of accurate reference values of children's renal sizes measured by ultrasonography cannot be overemphasised. ${ }^{2}$ Ultrasonography is without risk of ionising radiation and is therefore safe in the evaluation of growing children. It also provides a quick and accurate assessment of other visceral organ dimensions. ${ }^{3}$ Reports have demonstrated that renal length differs from race to race. ${ }^{4,5,6}$ The size and weight of an organ have also been shown to be influenced by environmental variations, ethnicity, hereditary components, routine diet, water intake $\mathrm{e}^{7,8}$ and high altitudes, where atmospheric pressure is reduced, with the partial pressure of oxygen altering the physiology of the kidneys. ${ }^{9}$

The kidneys can be affected by congenital or acquired diseases, either localised or systemic. Examples are solitary kidney, renal hypoplasia, ${ }^{10}$ multicystic and polycystic kidneys, acute malaria because of plasmodium falciparum, ${ }^{11}$ auto-immune diseases such as Kawasaki disease, ${ }^{12}$ recurrent urinary tract infection, neoplasms, urolithiasis, trauma, drugs, ingestion of native concoctions, diabetes, hypertension, renal artery stenosis and so on. Knowledge of renal size helps in differentiating acute from chronic kidney diseases (CKD). ${ }^{2,13}$ Chronic diseases include diseases that reduce the size of the kidneys such as chronic glomerulonephritis, nephrosclerosis and diabetic nephropathy, and those that increase its sizes such as multi- or polycystic kidney diseases and so on. In addition, renal length and volume are very important parameters for numerous purposes such as the assessment of candidates for/with kidney transplant, decision in obtaining renal biopsies and follow-up of patients with end-stage liver disease in which nephromegaly and increased echogenicity of renal cortex can be associated with pathological findings (renal size usually reverses after liver transplant). Kidney size is an 
important parameter used for the clinical evaluation of renal abnormalities, such as atrophy, hypoplasia and hypertrophy in children. Sonography is used to monitor the kidneys of children before and after liver transplants with sizes compared with published normative values. ${ }^{14}$ Renal involvement can be a part of a syndrome such as Beckwith-Wiedemann syndrome (BWS). This syndrome is reported to have a high risk of development of embryonic tumours such as Wilm's tumour. ${ }^{15}$ Screening protocols with ultrasonography have been implemented in some countries for the early detection of these tumours ${ }^{16}$ because a criterion for its diagnosis is evidence of renal enlargement.

A study by Jones et al. ${ }^{17}$ demonstrated that renal volume, which correlates better with renal mass, is a more sensitive means of diagnosing kidney abnormality than any single linear measurement. Also at autopsy, renal volume has been reported to correlate well but indirectly with the number of functioning nephrons, ${ }^{18}$ hence its inclusion in this study.

A Nigerian study on paediatric hospital admissions by Esezobar et al. ${ }^{19}$ showed that acute renal disease accounted for up to $82.9 \%$ of admissions. It is invaluable to have a more comprehensive, standardised, sonographic measurement for use in the course of the renal assessment of a child, hence this study.

\section{Materials and methods}

This was a descriptive, cross-sectional study of the kidney parameters of apparently healthy, school-aged, Nigerian children without any known renal disease. Whilst informed consent was received from the parents of the children, child assent was also obtained from each child involved in this study. Detailed medical history of each child was acquired from the parents including pre-existing diseases that could affect the kidneys, past urologic surgeries and known history of chronic diseases. After clinical examination of each child by one of the authors who is a clinician, only apparently healthy children were recruited for the study.

Clinical exclusion criteria were fever, periorbital or pedal edema, macular or maculopapular rashes and sickle cell anaemia. Imaging exclusion criteria were altered echogenicity, presence of renal cysts, urolithiasis, unilateral kidney, hydronephrosis, ureterocele, renal ectopia, horseshoe kidneys and other developmental anomalies, and neoplasm.

A total of 1315 children ( 633 boys and 682 girls) between the ages of 5 and 17 years were selected for this study using a random selection method. Age, sex and anthropometric measurement of the body size indicators such as weight (WT), height (HT), body surface area (BSA) and body mass index (BMI) were obtained for each subject. Using the vertical scale of a portable stadiometer, each participant was placed, without shoes, in an upright position with the head held in the Frankfort plane and the height measured to the nearest $0.5 \mathrm{~cm}$. With each participant lightly clothed, weight was measured with a weighing scale to the nearest $0.1 \mathrm{~kg}$.

Kidney parameters were obtained using a GE LOGIC 400CL ultrasound machine made by GE medical systems with a $3.5 \mathrm{MHz}$ curvilinear probe. Renal sizes by ultrasound were obtained by one of the authors who is a radiologist. To achieve greater accuracy, two sequential measurements were taken and the mean calculated. Kidney measurements were obtained with subjects in a prone position ${ }^{20}$ and in quiet respiration. The bipolar length of each kidney was measured from the highest to its lowest point. The width and thickness were obtained in the transverse plane in an orthogonal direction, near the renal hilum but free of the pelvis. The renal thickness or anterioposterior (AP) diameter, was measured in the same transverse plane with a line perpendicular to the width (at its central highest point), as shown in Figure 1. The probe therefore was not exactly perpendicular to the skin. No subject was included more than once. No sedation nor any preparation was used. The mean renal length and 5th and 95th percentiles were determined for each age. The BSA and BMI were calculated using the respective formulas:

BSA $=(\text { weight }(\mathrm{kg}) \times \text { height }(\mathrm{m}) / 3600)^{1 / 2}($ Mosteller formula $)$

$\mathrm{BMI}=$ weight $(\mathrm{kg}) /$ height $^{2}(\mathrm{~m})$.

Renal volume $=$ length $(\mathrm{cm}) \times$ width $(\mathrm{cm}) \times$ thickness $(\mathrm{cm}) \times$ 0.523 .

\section{Ethical considerations}

Ethical approval to conduct the study was obtained from the College of Medicine Research Ethics Committee, University of Nigeria Enugu Campus (Reference no. 070/06/2019).

\section{Results}

The mean values of the left and right renal dimensions of the various age groups of the studied population have been presented in Table 1. Table 2 presents a height-matched comparison, whilst Table 3 shows a weight-matched comparison. Table 4 presents the renal correlation. The regression formula for the various renal dimensions is presented in Table 5.

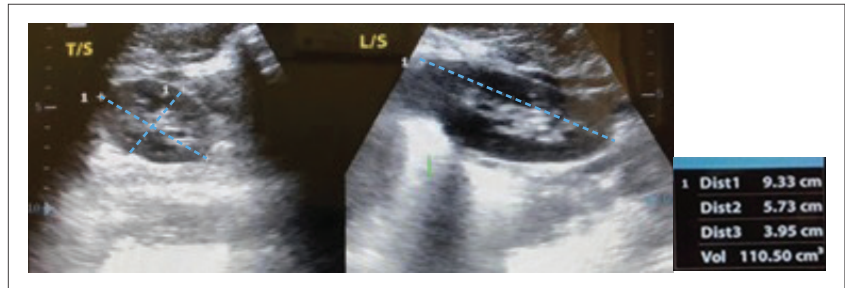

$\mathrm{T} / \mathrm{S}$, transverse scan; L/S, longitudinal scan; RK, right kidney. FIGURE 1: Showing points of measurements of a kidney. 

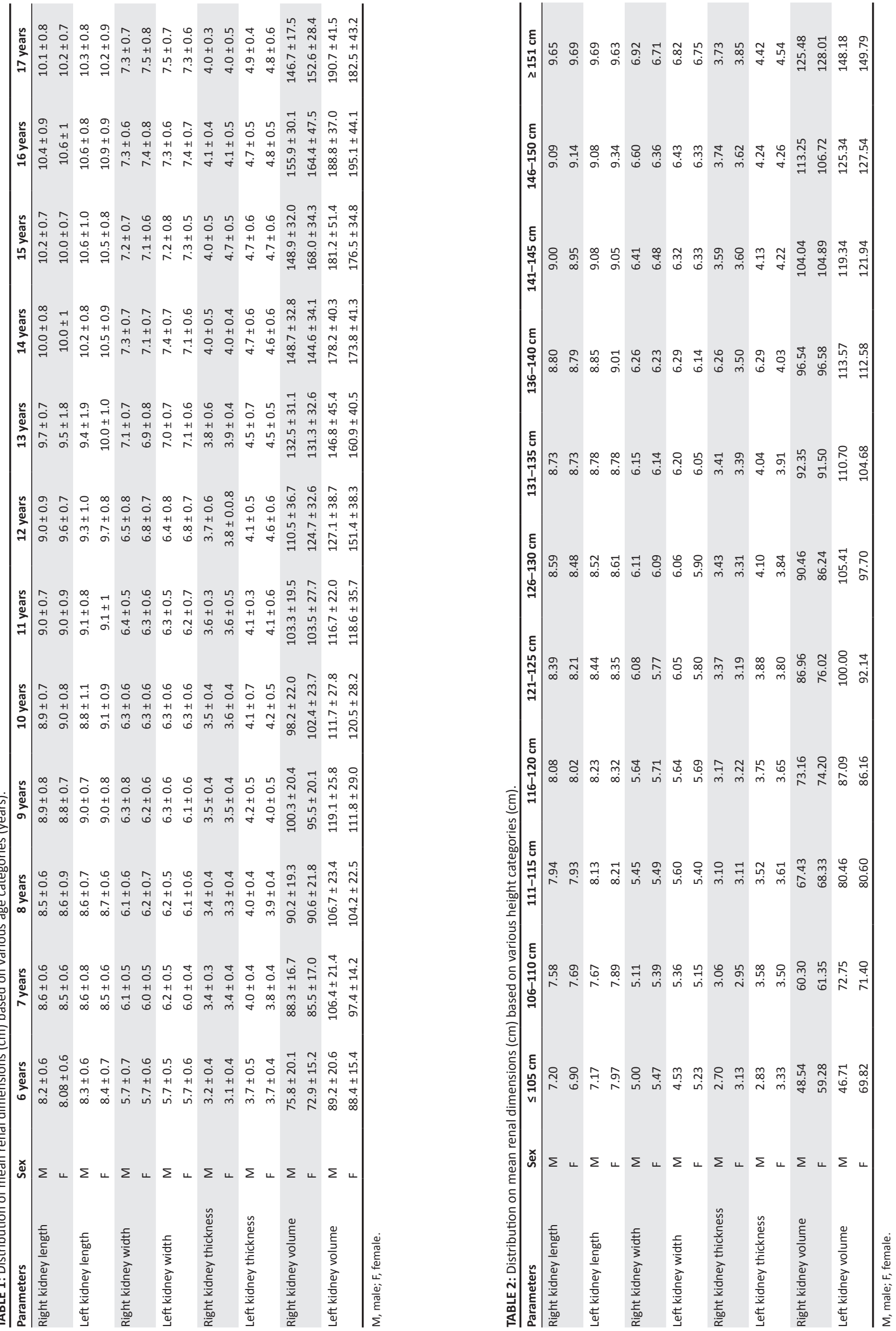
TABLE 3: Distribution of mean renal dimensions $(\mathrm{cm})$ based on various weight categories $(\mathrm{kg})$.

\begin{tabular}{|c|c|c|c|c|c|c|c|c|c|c|c|c|c|}
\hline Parameters & Sex & $15-20 \mathrm{~kg}$ & $21-25 \mathrm{~kg}$ & $26-30 \mathrm{~kg}$ & $31-35 \mathrm{~kg}$ & $36-40 \mathrm{~kg}$ & $41-45 \mathrm{~kg}$ & $46-50 \mathrm{~kg}$ & $51-55 \mathrm{~kg}$ & $56-60 \mathrm{~kg}$ & $61-65 \mathrm{~kg}$ & $66-70 \mathrm{~kg}$ & $\geq 70 \mathrm{~kg}$ \\
\hline \multirow[t]{2}{*}{ Right kidney length } & $M$ & 7.66 & 8.22 & 8.67 & 8.87 & 9.18 & 9.47 & 9.95 & 10.15 & 9.96 & 10.27 & 10.74 & 10.64 \\
\hline & $\mathrm{F}$ & 7.78 & 8.20 & 8.69 & 8.84 & 9.07 & 9.65 & 9.53 & 10.02 & 10.41 & 10.61 & 10.59 & 10.47 \\
\hline \multirow[t]{2}{*}{ Left kidney length } & M & 7.81 & 8.29 & 8.67 & 8.93 & 9.36 & 9.60 & 10.02 & 10.11 & 10.04 & 10.47 & 10.98 & 10.84 \\
\hline & $\mathrm{F}$ & 8.13 & 8.40 & 8.77 & 8.97 & 9.28 & 9.86 & 9.86 & 10.46 & 10.52 & 10.74 & 11.09 & 10.67 \\
\hline \multirow[t]{2}{*}{ Right kidney width } & M & 5.37 & 5.77 & 6.13 & 6.31 & 6.63 & 6.83 & 6.94 & 7.11 & 7.25 & 7.39 & 7.66 & 7.43 \\
\hline & $\mathrm{F}$ & 5.44 & 5.82 & 6.10 & 6.29 & 6.50 & 6.79 & 6.76 & 7.09 & 7.25 & 7.46 & 7.47 & 7.68 \\
\hline \multirow[t]{2}{*}{ Left kidney width } & M & 5.46 & 5.79 & 6.11 & 6.26 & 6.64 & 6.70 & 6.83 & 7.09 & 7.23 & 7.44 & 7.47 & 7.63 \\
\hline & $\mathrm{F}$ & 5.34 & 5.77 & 5.98 & 6.20 & 6.35 & 6.87 & 6.83 & 7.24 & 7.14 & 7.46 & 7.54 & 7.83 \\
\hline \multirow[t]{2}{*}{ Right kidney thickness } & M & 3.01 & 3.21 & 3.42 & 3.53 & 3.66 & 3.82 & 3.91 & 3.98 & 4.02 & 4.06 & 4.11 & 4.16 \\
\hline & $\mathrm{F}$ & 3.05 & 3.21 & 3.34 & 3.53 & 3.56 & 3.88 & 3.93 & 3.97 & 4.06 & 5.60 & 4.30 & 4.40 \\
\hline \multirow[t]{2}{*}{ Left kidney thickness } & M & 3.49 & 3.75 & 4.02 & 4.10 & 4.19 & 4.37 & 4.43 & 4.64 & 4.70 & 4.89 & 5.01 & 4.93 \\
\hline & $\mathrm{F}$ & 3.55 & 3.75 & 3.90 & 4.03 & 4.25 & 4.48 & 4.55 & 4.76 & 4.61 & 4.72 & 4.95 & 5.12 \\
\hline \multirow[t]{2}{*}{ Right kidney volume } & M & 62.67 & 77.07 & 91.29 & 103.74 & 116.46 & 130.18 & 142.17 & 151.41 & 152.92 & 161.63 & 176.79 & 171.72 \\
\hline & $\mathrm{F}$ & 65.08 & 77.18 & 89.01 & 98.50 & 105.87 & 127.66 & 129.50 & 141.66 & 154.79 & 217.68 & 172.29 & 178.05 \\
\hline Left kidney volume & $M$ & 74.76 & 90.67 & 106.49 & 121.02 & 137.67 & 148.62 & 160.71 & 174.88 & 179.40 & 199.96 & 216.94 & 215.32 \\
\hline
\end{tabular}

$\mathrm{M}$, male; $\mathrm{F}$, female.

TABLE 4: Correlation matrix coefficients of renal dimensions with age and body size indicators.

\begin{tabular}{|c|c|c|c|c|c|c|c|c|c|c|c|c|c|}
\hline Param & Age & eight & Weight & $\begin{array}{l}\text { Body } \\
\text { Mass } \\
\text { Index }\end{array}$ & $\begin{array}{c}\text { Body } \\
\text { Surface } \\
\text { Area }\end{array}$ & $\begin{array}{c}\text { Right } \\
\text { Kidney } \\
\text { Length }\end{array}$ & $\begin{array}{c}\text { Right } \\
\text { Kidney } \\
\text { Thickness }\end{array}$ & $\begin{array}{c}\text { Right } \\
\text { Kidney } \\
\text { Width }\end{array}$ & $\begin{array}{c}\text { Right } \\
\text { Kidney } \\
\text { Volume }\end{array}$ & $\begin{array}{c}\text { Left } \\
\text { Kidney } \\
\text { Length }\end{array}$ & $\begin{array}{c}\text { Left } \\
\text { Kidney } \\
\text { Thickness }\end{array}$ & $\begin{array}{c}\text { Left } \\
\text { Kidney } \\
\text { Width }\end{array}$ & $\begin{array}{c}\text { Left } \\
\text { Kidney } \\
\text { Volume }\end{array}$ \\
\hline se & 1 & & & 52 & 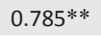 & $0.583^{* *}$ & $89 * *$ & $568 * *$ & $0.503 * *$ & $0.565 * *$ & $0.473 * *$ & $0.578 * *$ & $0.617 * *$ \\
\hline leight & $371 * *$ & 1 & 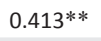 & $.101 * *$ & $* *$ & + & $8^{* *}$ & ** & $7 * *$ & $5 * *$ & $* *$ & $* *$ & $.339 * *$ \\
\hline Cigit & 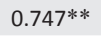 & 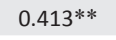 & 1 & 49 & ( & 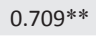 & +2 & $* *$ & 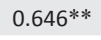 & $* *$ & 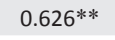 & $*$ & $0 * *$ \\
\hline Body Mass Index & .052 & $-0.101 * *$ & 0.049 & 1 & -0.001 & 0.051 & 0.010 & 0.005 & 0.040 & 0.034 & -0.002 & t. & 0.033 \\
\hline 3ody Surface Area & $785^{* *}$ & $0.955^{* *}$ & $0.979 * *$ & $-0.061 *$ & 1 & $0.719 * *$ & $0.384 * *$ & $0.676 * *$ & $0.639 * *$ & $0.701 * *$ & $0.628^{* *}$ & $0.699 * *$ & $0.788 * *$ \\
\hline Right Kidney Thickness & $0.289 * *$ & $0.158 * *$ & $0.388 * *$ & 0.010 & $0.384 * *$ & $0.323 * *$ & 1 & $0.373 * *$ & $0.890 * *$ & $0.317 * *$ & $0.338^{* *}$ & $0.360 * *$ & $0.396 * *$ \\
\hline Right Kidney Width & $0.568 * *$ & $0.280 * *$ & $0.671 * *$ & $0.069 *$ & $0.676 * *$ & $0.642 * *$ & $0.373 * *$ & 1 & $0.693 * *$ & $0.571 * *$ & $0.562 * *$ & $0.679 * *$ & $0.698 * *$ \\
\hline Right Kidney Volume & $0.503 * *$ & $0.267 * *$ & $0.646 * *$ & 0.040 & $0.639 * *$ & $0.658^{* *}$ & $0.890 * *$ & $0.693 * *$ & 1 & $0.566 * *$ & $0.516^{* *}$ & $0.598 * *$ & $0.659 * *$ \\
\hline Left Kidney Length & $0.565^{* *}$ & $0.315^{* *}$ & $0.690 * *$ & 0.054 & $0.701 * *$ & $0.715 * *$ & $0.317^{* *}$ & $0.571 * *$ & $0.566 * *$ & 1 & $0.465^{* *}$ & $0.647 * *$ & $0.817 * *$ \\
\hline Left Kidney Thickness & $0.473 * *$ & $0.263 * *$ & $0.626 * *$ & -0.002 & $0.628 * *$ & $0.513 * *$ & $0.338 * *$ & $0.562 * *$ & $0.516 * *$ & $0.465 * *$ & 1 & $0.642 * *$ & $0.820 * *$ \\
\hline Left Kidney Width & $0.578^{* *}$ & $0.313 * *$ & $0.694 * *$ & 0.043 & $0.699 * *$ & $0.633 * *$ & $0.360 * *$ & $0.679 * *$ & $0.598 * *$ & $0.647 * *$ & $0.642 * *$ & 1 & $0.885 * *$ \\
\hline Left Kidney Volume & $.617 * *$ & $0.339 * *$ & $0.790 * *$ & 0.033 & $0.788 * *$ & $0.714 * *$ & $0.396 * *$ & $0.698 * *$ & $0.659 * *$ & $0.817 * *$ & $0.820 * *$ & $0.885 * *$ & 1 \\
\hline
\end{tabular}

$*, p<0.05 ; * *, p<0.01$.

TABLE 5: Distribution of the regression formula for the various renal dimensions using age and body size indicators.

\begin{tabular}{lll}
\hline Dependent variable & Regression formula & $p$-value \\
\hline Right Kidney Length & $(5.91)+$ Age $(0.04)+$ HT $(0.01)+$ WT $(0.03)$ & $<0.0001$ \\
Right Kidney Thickness & $(2.43)+$ Age $(0.004)+$ HT $(0.002)+$ WT $(0.02)$ & $<0.0001$ \\
Right Kidney Width & $(4.48)+$ Age $(0.04)+$ HT $(0.004)+$ WT $(0.02)$ & $<0.0001$ \\
Left Kidney Length & $(5.58)+$ Age $(0.05)+$ HT $(0.01)+$ WT $(0.021)$ & $<0.0001$ \\
Left Kidney Thickness & $(2.68)$ - Age $(0.004)+$ HT $(0.005)+$ WT $(0.03)$ & $<0.0001$ \\
Left Kidney Width & $(4.23)+$ Age $(0.043)+$ HT $(0.005)+$ WT $(0.03)$ & $<0.0001$ \\
Right Kidney Volume & $(30.67)+$ Age $(0.64)-$ HT $(0.003)+$ WT (2.06) & $<0.0001$ \\
Left Kidney Volume & $(33.91)+$ Age $(0.079)+$ HT $(0.02)+$ WT (2.39) & $<0.0001$ \\
\hline
\end{tabular}

Significant asymmetry was noted in all the measured renal parameters. Whilst the left renal length, thickness and volume were greater than those of the right in all the age-, weight- and height-matched categories $(p<0.01)$, the reverse was noted for the right renal width. Significant sexual dimorphism was observed in the kidney dimensions $(p<0.05)$. The left kidney was significantly longer in females $(p<0.05)$ in the age and weight categories, whilst the males showed significantly wider kidneys in all the categories (age, height and weight). Females were also noted to have thicker kidneys in most of the categories (age and weight) and larger volume in all the categories than males, though without statistical significance $(p>0.05)$.
Of those who did not meet the imaging inclusion criteria, six subjects were found to have some congenital renal pathologies. Two of these six children had unilateral kidneys, one subject had a left ureterocele with gross left-sided hydronephrosis whilst the three remaining subjects had ectopic kidneys visualised in the pelvis. These abnormal findings were communicated to the parents of each of these children. The final study sample size was 1315.

\section{Discussion}

Several studies on renal sizes have been reported in neonates / infants, ${ }^{15,21,22,23}$ children, ${ }^{14,24,25,26,27,28}$ adults ${ }^{4,6,29,30,31}$ and geriatric subjects. ${ }^{5,32}$ This study shows that the left kidney is longer, thicker and more voluminous than the right kidney. This is consistent with previous reports $22,26,33,34$ but contrary to research that noted that there is no statistical difference between the left and right kidneys. ${ }^{20,35}$

Sexual dimorphism was observed in our study - the left kidney in females was longer than the left kidney of males when age- and weight-matched. This is in agreement with studies conducted in New York by Chen et al. ${ }^{24}$ In addition, sexual dimorphism was noted in another study in infants. ${ }^{22}$ 
However, some other researchers showed no sexual dimorphism in their reports, although some commented that the rate of general somatic growth and body proportion are different between boys and girls. 2,25,26,28,33,36

Studies carried out on Indian and Chinese children ${ }^{25,37}$ showed a progressive increase in renal length and volume with age. This increase with age was not consistent in our study population until 9 years of age and beyond. The difference in the number of participants within each of the groups and/or variations in the nutritional levels of the children in these particular age groups may be contributory factors to this observation.

The renal parameters in our study correlated best with BSA and weight $p<0.05$. This is in agreement with some reports ${ }^{38,39}$ but contrary to other studies ${ }^{10,34,36,38,40,41}$ in which there was best correlation with height. Yet, other researchers have reported correlation with both height and weight. $28,42,43,44$ Oh et al. ${ }^{2}$ observed that height is the most influencing factor amongst the somatic variables in children $<2$ years of age, whilst weight and age have good correlation with renal length from 2 to 12 years of age. A study by Pantoja et al. ${ }^{42}$ also noted that the kidneys were significantly larger in the obese subjects than in children with normal weights. Previous reports in low birth weight infants and premature deliveries have observed that these children have low nephron number and therefore reduced renal volumes ${ }^{45,46,47}$ and discovered they have a related risk of hypertension and renal diseases. ${ }^{45}$ One can speculate that the bigger the body size of a person, the higher the nephron number to take care of the body's metabolic needs.

Previous Nigerian-based results on renal parameters of adults ${ }^{30,48}$ demonstrated that the renal parameters correlated best with weight compared with the current study where BSA had the strongest correlation followed by weight. We have demonstrated that age and all the body size indicators significantly correlate $(p<0.01)$ with all the renal dimensions with the exception of BMI which is in agreement with reports by Younus et al. ${ }^{28}$ that BMI may not be a good predictor of renal measurement. However, this is contrary to another report where BMI was demonstrated to significantly relate to renal length. ${ }^{42}$

The prevalence of congenital anomaly as revealed in this study was $0.46 \%$ which is slightly lower than the $0.89 \%$ recorded by Scott et al. ${ }^{22}$ in a similar study carried out in infants.

\section{Conclusion}

We have established age-, weight- and height-specific normal values of the kidneys in apparently healthy Nigerian children and developed regression equations for adequate evaluation and follow-up of renal diseases in clinical radiology and general medicine. We also noted significant sexual dimorphism and bilateral asymmetries in the kidney parameters of the studied population.

\section{Limitation of the study}

Urinalysis, serum electrolyte, urea and creatinine or glomerular filtration rate tests were not carried out for the study population, which may have further eliminated possibilities of including children with renal diseases. These investigations are more specific for kidney function than they are for renal morphology, which is the focus of this work.

\section{Acknowledgements Competing interests}

The authors declare that they have no financial or personal relationships that may have inappropriately influenced them in writing this article.

\section{Authors' contributions}

All authors contributed equally to this work.

\section{Funding information}

This research received no specific grant from any funding agency in the public, commercial or not-for-profit sectors.

\section{Data availability statement}

Data may be made available by the corresponding author, on request.

\section{Disclaimer}

The views and opinions expressed in this article are those of the authors and do not necessarily reflect the official policy or position of any affiliated agency of the authors.

\section{References}

1. Kadioglu A. Renal measurements, including length, parenchymal thickness, and medullary pyramid thickness, in healthy children: What are the normative ultrasound values? Am J Roentgenol. 2010;194(2):509-515. https://doi. org/10.2214/AJR.09.2986

2. Oh M-S, Hwang G, Han S, et al. Sonographic growth charts for kidney length in normal Korean children: A prospective observational study. J Korean Med Sci. 2016;31(7):1089-1093. https://doi.org/10.3346/jkms.2016.31.7.1089

3. Buchholz NP, Abbas F, Biyabani SR, Javed Q, Talati J. Ultrasonographic renal size in individuals without known renal disease. J Pak Med Assoc. 2000;50(1):12-16.

4. Kang K-Y, Lee YJI, Park SC, et al. A comparative study of methods of estimating kidney length in kidney transplantation donors. Nephrol Dial Transplant. 2007;22(8):2322-2327. https://doi.org/10.1093/ndt/gfm192

5. Van Den Noortgte N, Velghe A, Petrovic M, et al. The role of ultrasonography in the assessment of renal function in the elderly. J Nephrol. 2003;16(5):658-662.

6. Miletic D, Fuckar Z, Sustic A, Mozetic V, Stimac D, Zauhar G. Sonographic measurement of absolute and relative renal length in adults. J Clin Ultrasound. 1998;26(4):185-189. https://doi.org/10.1002/(sici)1097-0096(199805)26:4<185 ::aid-jcu1>3.0.co;2-9

7. Sheikhazadi A, Sadr SS, Ghadyani MH, et al. Study of the normal internal organ weights in Tehran's population. J Forensic Leg Med. 2010;17(2):78-83. https:// doi.org/10.1016/j.jflm.2009.07.012

8. Caglar V, Kumral B, Uygur R, Alkoc OA, Ozen OA, Demirel H. Study of volume, weight and size of normal pancreas, spleen and kidney in adults autopsies. FMAR. 2014;2(1):63-69. https://doi.org/10.4236/fmar.2014.23012

9. Musa MJ, Abukonna A. Sonographic measurement of renal sizes in normal high altitude populations. J Radiat Res Appl Sci. 2017;10(3):178-182. https://doi. org/10.1016/j.jrras.2017.04.004

10. Cain JE, Di Giovonni V, Smeeton J, Rosenblun ND. Genetics of renal hypoplasia: Insights into the mechanism of controlling nephron endowment. Pediatr Res. 2010;68(1):91-98. https://doi.org/10.1203/PDR.0b013e3181e35a88 
11. Atalabi OM, Orimadegun A, Adekanmi AJ, Akinyinka O. Ultrasonography renal sizes, cortical thickness and volume in Nigerian children with acute falciparum malaria. Malar J. 2013;12(1):92. https://doi.org/10.1186/1475-2875-12-92

12. Huang H-P, Lai Y-C, Tsai I-J, Chen S-Y, Cheng C-H, Tsau Y-K. Nephromegaly in children with Kawasaki disease: New supporting evidence for diagnosis and its possible mechanism. Pediatric Res. 2008;63(2):207-210. https://doi.org/10.1203/ PDR.0b013e31815ef737

13. Faubel S, Patel NU, Lockhart ME, Cadnapaphornchai MA. Renal relevant radiology: Use of ultrasonography in patients with AKI. Clin J Am Soc Nephrol. 2014;9(2):382-394. https://doi.org/10.2215/CJN.04840513

14. Currarino G, Williams B, Dana K. Kidney length correlated with age: Normal values in children. Radiology. 1984:150(3);703-704. https://doi.org/10.1148/radiology. 150.3.6695070

15. De Baun MR, Siegal MJ, Choyke PL. Nephromegaly in infancy and early childhood: A risk factor for Wilm's tumour in Beckwith-Weideman Syndrome. J Pediatr. 1992;132(3Pt1):401-404. https://doi.org/10.1016/s0022-3476(98) 70009-5

16. Ortiz-Neira CL, Traubici J, Alan D, et al. Sonographic assessment of real growth in patients with Beckwith - Weidemann syndrome: The Beckwith - Weidemann syndrome real nomogram. Clinics. 2009;64(1):41-44. https://doi.org/10.1590/ s1807-59322009000100008

17. Jones $T$, Riddick L, Harpen $M$, Dubusisson R, Smuels D. Ultrasonographic determination of renal mass and renal volume. J. Ultrasound Med. 1983;2(1):151-154.

18. Nyengaard J, Bendtsen T. Glomerular number and size in relation to age, kidney weight and body surface in normal man. Anat Rec. 1992;232(2):194-201. https:// weight and body surface in norm
doi.org/10.1002/ar.1092320205

19. Esezobor Cl, Ladapo TA, Osinaite B, Lesi FE. Paediatric acute kidney injury in a tertiary hospital in Nigeria; prevalence, causes and mortality rate. PLoS One. 2012;7(12):e51229. https://doi.org/10.1371/journal.pone.0051229

20. Emamian SA, Nielson MB, Pederson JF, Ytte L. Kidney dimensions at sonography correlation with age, sex and habitus in 665 adult volunteers. AJR. 1993;160(1):83-86. https://doi.org/10.2214/ajr.160.1.8416654

21. Zerin JM, Meuer RD. Sonographic assessment of renal length in the first year of life: The problem of 'spurious nephromegaly'. Pediatr Radiol. 2000;30(1):52-57. https://doi.org/10.1007/s002470050014

22. Scott JES, Hunter EW, Lee REJ, Mathews JNS. Ultrasound measurement of renal size in new born infants. Arch Dis Childhood. 1990;65(4):361-364. https://doi. org/10.1136/adc.65.4_spec_no.361

23. Soyupak SK, Narli N, Yapicioglu H, Satar M, Sungur EH. Sonographic measurements of the liver, spleen and kidney dimensions in the healthy term and preterm newborns. Eur J Radiol. 2002;43(1):73-78. https://doi.org/10.1016/s0720048x(01)00466-1

24. Chen JJ, Pugach J, Patel M, Luisiri A, Steinhardt GF. The renal length Normogram: A multivariable approach. J Urol. 2002:168(5);2149-2152. https://doi. A multivariable approach. J Urol.
org/10.1016/S0022-5347(05)64339-X

25. Otiv A, Mehta K, Ali U, Nadkarni M. Sonographic measurement of renal size in normal Indian children. Indian Pediatrics. 2012;49(7):533-536. https://doi. org/10.1007/s13312-012-0120-7

26. Dinkel E, Erter $M$, Peters $H$, Berres $M$, Schulte-Wissermenn $H$. Kidney size in childhood: Sonographic growth charts for kidney length and volume. Pediat Radiol. 1985;15(1):38-43. https://doi.org/10.1007/BF02387851

27. Safak AA, Simek E, Talat B. Sonographic assessment of the normal limits and percentile curves of liver, spleen and kidney dimensions in healthy school-aged children. J Ultrasound Med. 2005;24(10):1359-1364. https://doi.org/10.7863/ jum.2005.24.10.1359

28. Younus N, Raza F, Bhugio S, et al. Sonographic measurement of normal renal size and correlation with somatic variables in subset of Karachi pediatric population. Pakistan J Med Dent. 2015;4(2):24-29.

29. Njeze NR, Okeke DO, Ezeofor SN, Onodugo OD. The effect of advancing age on absolute renal length. West Africa J Radiol. 2011;18(1):16-18.
30. Okoye IJ, Agwu KK, Idigo FU. Normal sonographic renal length in southeast Nigeria. Afr J Med Sci. 2005;34(2):129-131.

31. Oyuela-Carrasco J, Rodriguez-Castellanos F, Kimura E, Delgado-Hemandez R, Herrera-Felix JP. Renal length measured by ultrasound in adult Mexican 2009.29.1.30.1.en.full.pdf

32. Akpainar IN, Altun E, Avcus S, Tuney D, Ekinci G, Biren T. Sonographic measurement of kidney size in geriatric patients. J Clin Ultrasound. 2003;31(6):315-318. https:// doi.org/10.1002/jcu.10178

33. Han BK, Babcock DS. Sonographic measurement and appearance of normal kidney in children. AJR. 1985;145(3):611-616. https://doi.org/10.2214/ajr.145.3.611

34. Eze CU, Agwu KK, Ezeasor DN, Agwuna KK, Aronu AE, Mba El. Sonographic biometry of normal kidney dimensions among school-aged children in Nsukka, Southeast Nigeria. West Indian Med J. 2014;63(1):46-53. https://doi.org/10.7727/ wimj.2013.010

35. Abdoerlrahman HAB, Mansour AA, Gar-elnabli MEM, Saeed EA. Ultrasound renal length and parenchymal thickness in normal Sudanese population. Int J Sci Res. 2016;5(1):623-625.

36. Konus OL, Ozdemic A, Allaya A, Erbas G, Celik H, Isik S. Normal liver, spleen and kidney dimensions in neonates, infants and children: Evaluation with sonographic. ARJ. 199;171(6):1639-1698. https://doi.org/10.2214/ajr.171.6.9843315

37. Loftus WK, Gent RJ, LeQuesne GW, Metreweli C. Renal length in Chinese children: Sonographic measurement and comparison with western data. J Clin Ultrasound. 1998;26(7):349-352. https://doi.org/10.1002/(sici)1097-0096(199809)26:7<349 ::aid-jcu4>3.0.co;2-9

38. Kim J-H, Kim M-J, Sok HL, Jieun K, Lee M-J. Length and volume of morphologically normal kidneys in Korean children: Ultrasound measurement and estimation using body size. Korean J Radiol. 2013;14(4):677-682. https://doi.org/10.3348/ kjr.2013.14.4.677

39. Saeed Z, Mirza W, Sayami R, Sheikh A, Yazdani I, Hussain SA. Sonographic measurement of renal dimensions in adults and its correlates. Int J Collab Res Intern Med Public Health. 2012;4(9):1626-1641.

40. Rousan LA, Fataftah J, Al-Omari MH, Hayajneh WA, Miqdady M, Khader YS Sonographic assessment of kidney length in Jordanian children: Results from a tertiary hospital in the North of the Kingdom. J Med J. 2015;49(2):101-107.

41. Kim BW, Song MK, Chung S, Kim KS. Evaluation of kidney size in children: A pilot study of renal length as a surrogate of organ. Korean J Pediatr. 2012;55(2):54-57. https://doi.org/0.3345/kjp.2012.55.2.54

42. Pantoja ZJR, Mallios R, Murphy J. The effect of obesity on kidney length in a healthy pediatric population. Pediatr Nephrol. 2009;24(10):2023-2027. https:// doi.org/10.1007/s00467-009-1202-1

43. Glodny B, Unterholzner V, Taferner B, et al. Normal kidney size and its influencing factors-a 64-slice MDCT study of 1.040 asymptomatic patients. BMC Urol. 2009;9(1):19. https://doi.org/10.1186/1471-2490-9-19

44. Kim JH, Kim MJ, Lim SH, Kim J, Lee MJ. Length and volume of morphologically normal kidneys in Korean children: Ultrasound measurement and estimation using body size. Korean J Radiol. 2013;14(4):677-682. https://doi.org/10.3348/ kjr.2013.14.4.677

45. Luyckx VA, Shukha K, Brenner BM. Low nephron number and its clinical consequences. Rambam Maimonides Med J. 2011;2(4):e0061. https://doi. org/10.5041/RMMJ.10061

46. Spencer J, Wang Z, Hoy W. Low birth weight and reduced renal volume in aboriginal children. Am j Kidney Dis. 2001;37(5):915-920. https://doi. org/10.1016/s0272-6386(05)80006-x

47. Kandasamy $Y$, Smith R, Wright IM, Lumbers ER. Relationships between glomerular filtration rate and kidney volume in low birth weight neonates. I Nephrol. 2013;26(5):894-898. https://doi.org/10.5301/jn.5000220

48. El-Reshaid W, Abdul-Fattah H. Sonographic assessment of renal size in healthy adults. Med Princ Pract. 2014;23(5):432-434. https://doi.org/10.1159/00036 4876 